\title{
SUSTAINABLE TOURISM -A CASE STUDY OF CHENNAI AND SINGAPORE
}

\author{
Dr. P. Raja \\ Assistant Professor, Department of Tourism and Hospitality Management, \\ Central university of Tamilnadu, Neelakudy, Tamil Nadu, India \\ Dr. A. Raghu \\ Associate Professor, Department of Tourism and Hospitality Management, \\ Central university of Tamilnadu, Neelakudy, Tamil Nadu, India
}

\begin{abstract}
Tourism is promoted and appreciated for its ability to promote and encourage "development". This development is generally is attaining through the use of natural and cultural resources. "Development" is a growth or a stage of growth, it is a process of change and this change can be in many ways Tourism as an industry has the greatest potential for growth and is the fastest growing industry of the world. In this pace of development of this industry there are many ethical and moral issues that need to be taken care of. Now there is a new side to this industrial development which is the political impact and development. The tourism industry generates huge money and this money should be again used to further develop and promote the tourist place. This paper clearly deprives the Importance of Sustainable Tourism and how it has been proved a Success story In Singapore in terms of Tourism Sustainability.
\end{abstract}

Key words: Sustainable Tourism, Generate new employment, Descriptive models, Preconditions, Environmental.

Cite this Article: P. Raja and A. Raghu, Sustainable Tourism -A case study of Chennai and Singapore, International Journal of Management (IJM), 11(12), 2020, pp. 30013012.

http://iaeme.com/Home/issue/IJM?Volume=11\&Issue=12

\section{INTRODUCTION}

Usually the two models that help to understand development are Explanatory and Descriptive models. The development of tourism is an overall growth of many other connected industries like the hospitality, food and beverage industry, transport sector, and also government agencies that specialises in tourism. It is a sector which can create multiple dependent jobs and generate new employment. 


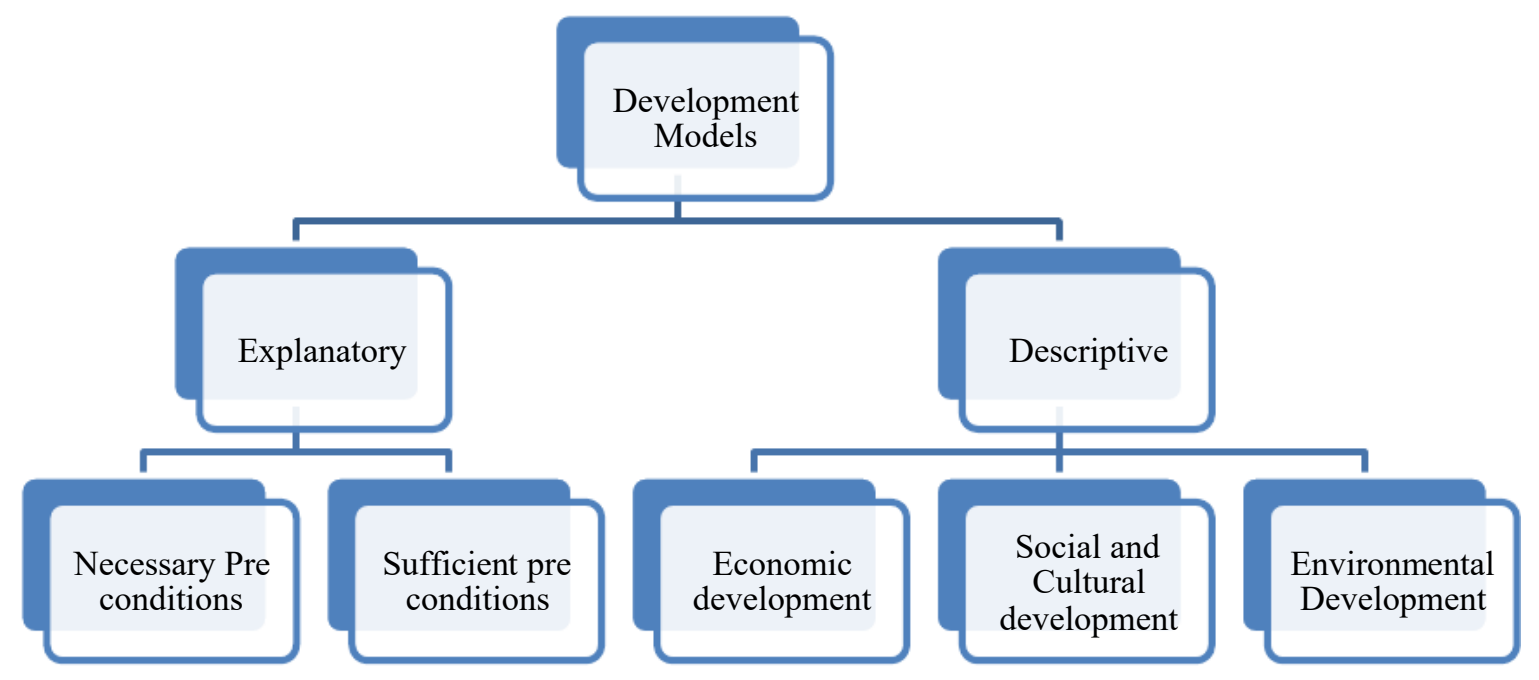

Figure 1

Source: Compiled from Clarke, J. (1997). A framework of approaches to sustainable tourism. Journal of Sustainable Tourism, 5

Explanatory models refer to preconditions for development namely the necessary preconditions and the sufficient preconditions. Necessary preconditions include various factors that may be called the pull factors for people to go into different destinations like nice, the explanatory model for development states that unless there are sufficient preconditions there cannot be development. Descriptive models examine tourism to be what appears on the ground like the infrastructure facilities like large hotels, facilities, transport etc. In this study, this model of development is more into prominence since this study about the actual impact of tourism development from not just the economic perspective but from the social cultural and environmental perspective. The present available resources should be desirable to create a new creative future and this process of generating a desirable present for a creative future is called interactive planning. There are 3 major types of interactive planning process in tourism. They are Participative planning which is also called participatory principle, continuity principle and holistic principle. In Participative principle all the stakeholders of tourism industry will participate in the planning process. The continuity principle is about the values of the industry change and uncertainty exists therefore planning process should be updated continuously and holistic principle talks about the different components of the tourism industry. The interactive planning which is participatory becomes very important in tourism industry since all the stakeholders participate and also contribute to the growth of the industry. The best benefit of this interactive participatory planning is that all the stakeholders get prepared to meet the objectives of the tourism industry. When thew objectives become clear then the methods by which these objectives can be reached become more clear and assessable.

The impact of tourism planning can be measured in many ways. The major impact assessed are economic, environmental and social. Income and expenditure and trade can be parameters for tourism impact in economic terms. The tourism receipt, increase in gross income of the people located in tourist areas etc can be used to evaluate the economic impact of tourism. Environmental impact is a great measure to assess tourism growth. There are many countries which have made it mandatory to pass regulations regarding environmental impact assessment (ELA) for all the tourism based projects. In EIA environmental audits are conducted to check the positive and negative impact due to the growth of tourism in that particular region. The environmental impacts include water management and use, land degradation and open space planning, drainage and sewage, recycling of wastes and garbage disposal, use of power etc. 
Social impact of tourism is also evaluated by the change in society, employment, culture of the people etc.

\section{AIM \& OBJECTIVES}

The overall aim of the research is:

- To explore the meaning and practical application of sustainable tourism development

- To determine how the concept of sustainable tourism development is perceived and understood by key tourism stakeholders.

- To identify the extent to which Singapore has 'embed' sustainable tourism development principles into their planning tourism development and management practices.

- To explore the significance of sustainability in India particularly in Chennai in the context of tourism and the suggestions of the best practices of Singapore in tourism development in Indian and especially in Chennai

\section{NEED FOR THE RESEARCH}

The benefits of tourism development are often accompanied by negative impacts which degrade the social and environmental context in which tourist interactions occur. Sustainable tourism development has been recognised as a means of addressing this issue. However, to date, there has been a lack of research evaluating the understanding and application of sustainable tourism development in Tourism. This research addresses this gap. Unsurprisingly, just as the number of people engaging in tourism has increased, so too has the value of the tourism industry. Although on the one hand it is encouraged to stimulate economic growth, on the other it is criticised for its social and environmental destruction. If tourism is to continue being used as a - tool for development, there is a need to acknowledge the importance of each of these dimensions and strive for a balance between competing objectives. In recent years, it has been suggested that the solution to this dilemma is "sustainable tourism development", a concept which applies the principles of the wider sustainable development paradigm to the specificities of the tourism industry. This research uses a qualitative research strategy was adopted which utilised a multi-case study methodology involving the major Tourists destinations in Chennai and Singapore. The concept of sustainability in tourism should not be seen as an end-goal, but as an on-going process, with the principles embedded into planning and management processes if progress is to be achieved.

\section{RESEARCH METHODOLOGY}

This research was primarily concerned with the interpretation of concepts, the role of individuals and Government in Sustainable development and the impacts of tourism. It adopted a case study approach that compared and contrasted the experiences. On this basis, a qualitative approach was deemed to be the most appropriate research strategy. Case study data collection involving multiple sources of information (e.g., observations, interviews, audiovisual material and documents and reports) and reports a case description and case-based themes. This research is specifically focused on the understanding and application of sustainable tourism This research uses two case studies one each in Chennai and Singapore to examine the understanding and application of sustainable tourism development in Tourism ... Both areas have a long history of tourism and possess well established industries, with developed planning and management systems. In addition, prior to commencement of the research, key contacts within both areas were identified who were willing to participate in the study to ensure that sufficient data could be accessed. 


\section{REVIEW OF LITERATURE}

For better understanding of the review of literature, the sources of literature reviewed have been classified into sub classifications such as

- Tourism and Development

- Tourism and Sustainability

\subsection{Tourism and Development}

Although, there is pervasive tourism growth in the last decade and the use of tourism by many countries is used as a development strategy, literature in this concept of tourism and development is almost neglected. Rostow (1960) ${ }^{10}$ identifies a natural path to economic growth which all societies or nations have to follow if they want to become modern. This path includes five stages beginning with traditional society and progressing through the stages of preconditions for takeoff and then the actual take off and drive to maturity and stage before mass consumption and then the mass consumption stage. He recognised the role played by the private sector for the accelerated growth and development of tourism

Developing countries often benefit from their abundance of 'free' natural and cultural resources, which provides the opportunity to develop a tourist industry with relatively minimal start up costs. The growing demand for authentic tourism experiences away from crowded, over-commercialised, polluted resorts) provide them with the chance to market themselves as 'unspoilt' destinations this concept of tourism and development is very clearly high lightened by Cohen, $1988^{11}$.

Developed nations however, often have a plethora of industries which contribute to income and broader development and thus, often do not place tourism in as high a regard as developing nations. However, it is still recognised for its potential to produce significant economic benefits. Thus, whilst the nature of tourism development may be different in developed countries, the motivations behind its pursuit are often essentially the same says Reid, 2003. ${ }^{12}$

Tourism can be used to redistribute wealth and employment opportunities and reduce the disparities between regions. This concept is brought forward by Hannigan, 1994. ${ }^{13}$. Almost the same concept of how tourism can help stimulate rural economies which are experiencing declining agricultural sectors and can be a valuable regeneration tool in post-industrial urbanisation is given by Briedenhann \& Wickens, $2004{ }^{14}$. May be the first time since the talk of tourism development, Mckercher in $1993{ }^{15}$ has brought out that while tourism can stimulate economic growth, it is by no means a 'smokeless' industry (McKercher, 1993) and can also negatively impact host communities and the natural environment both in developing and developed countries.

Tourism is reliant on the natural and cultural environment in which it exists. Despite the perceived economic benefits, the detrimental social and environmental impacts essentially mean that tourism can be a self-destructive industry, with visitors degrading or destroying the very environment which they have come to experience, this is what is stated by Cronin, 1990 ${ }^{16}$ This is particularly problematic for areas that rely heavily on tourism as their primary source of income as the decline of tourist numbers can significantly impact the local communities. However, high tourist numbers can also be detrimental to an area, with key problems at a local level including environmental degradation, overcrowding, congestion, resource depletion, ecosystem damage, disruption to local communities, the commoditisation of culture and the interests of tourists being prioritised over local needs It is evident therefore that a "tourismdevelopment dilemma" exists says Telfer \& Sharpley, 2008.$^{17}$ 


\subsection{Sustainable Tourism}

Early development theories of both tourism and sustainability concentrated on the top down approach of economic development having more priority than other social or human needs, the concept of environmental safety in tourism was thought of much later. However, with the growing population, increasing demand for tourism and depleting resources, the concept of optimum utilisation of the available resources and at the same time preserving the environment for future use has become very popular. This concept of sustainable development has caught the attention of not just the environmentalists but also the economists and the academicians. Slowly the concept of sustainability has been well received in all fields including tourism.

Sustainable development is one of the fundamental theories underpinning this research. Whilst this study specifically looks at the application of the concept within a tourism context, in order to properly understand the term and its key principles, it is first necessary to review the term from a broader stance. However, whilst the concept was the first to articulate the links between developments and the environmental, in practice, development has always impacted the environment, contributing to issues such as over-population, exploitation of natural resources and pollution. Various conservation movements were established in the late nineteenth century in response to the impacts of industrialisation and modernisation It was not until the 1960s however, that environmental concern moved beyond the conservation and protection of natural areas and species towards a broader environmentalist ideology. The environmental problems associated with increased industrialisation (e.g. water and air pollution) did not adhere to national boundaries and what happened in one area of the world ultimately impacted societies in other areas. It was these realisations that led to the emergence of 'environmental sustainability'. In this, developed countries are better placed to consider their environmental impact because they have already undergone development and attained a level of self-sufficiency. However, committing to sustainable development, e.g. by changing resource usage to more environmentally friendly methods, is not so easy for developing countries and nor is it considered particularly fair. Throughout periods of intense industrialisation, western countries had no restriction on their environmental impact and were able to use their natural resources however they saw fit. In theory then, should developing countries not be afforded the same opportunities for growth and development? Indeed, the priority for many developing countries is their short-term survival and they rely on the use of natural resources in order to achieve economic development and overcome extreme poverty consideration of environmental impacts and the needs of future generations are therefore often a secondary consideration in poorer nations, making sustainable development somewhat difficult to operationalise. However, despite sustainable development being largely embraced as a development paradigm, one particular problematic issue is the interchangeable use of the terms sustainable development and sustainability. Although related, there are significant differences between them. Sustainability was originally a concept embedded in ecology where it was used to refer to the ongoing maintenance of the natural environment. Thus, sustainability can be viewed as the end goal, whilst sustainable development is the process of achieving that goal ${ }^{1}$

"Sustainable tourism means accepting a commitment to providing healthy long-term tourism thoroughly integrated with the other elements of economy and with environment and society in such a manner that a policy change in one does not duly interfere with the optimal functioning of any of the others ${ }^{2}$. Sustainable tourism now can be said to represent a set of principles, policy a plan of action and management methods that draw a path for tourism development in which there is an environmental resource base (including natural, built, social and cultural features) which is protected for future development". 3 "Tourism, as it relates to sustainable development, is tourism which is developed so that the nature, scale, location and 
manner of development is appropriate and sustainable over time, and where the environment's ability to support other activities and processes is not impaired, since tourism cannot be isolated from other resource use activities as a tourism-centric approach to sustainability." " 4 "Sustainable tourism development is accepted as all kinds of tourism developments that make a notable contribution to or, at least, do not contradict the maintenance of the principles of development in an indefinite time without compromising the ability of future generations to satisfy their own needs and desires." "Sustainable tourism development guidelines and management practices are applicable to all forms of tourism in all types of destination, including mass tourism and the various niche tourism segments.

Given the definitional difficulties associated with sustainable tourism development, it is perhaps more useful to interpret the concept according to its key objectives. The objectives are as follows: sustainable tourism development should:

- To make judicious use of environmental resources to develop tourism and at the same time maintaining essential ecological process and helping to conserve natural heritage and biodiversity;

- To encourage and accept the socio-cultural authenticity of host communities, conserve their cultural heritage and traditional values and contribute to inter-cultural understanding and tolerance;

- To ensure stable employment and income earning viable, long-term economic operations, providing opportunities and social services to host communities and contributing to poverty alleviation. ${ }^{6}$

It is essential that tourism needs are met so that the destination can continue to attract visitors and support a long-term viable tourism industry. This issue is often neglected within sustainable tourism literature, with it taken for granted that destinations will inevitably experience tourism demand ${ }^{7}$. However, this is not always the case and it is important not to assume that there will a constant flow of tourists to a destination. Tourism is vital for many areas, with income providing financial support to ensure the continued existence of destinations and their related economies and contributing to broader development goals ${ }^{8}$. The challenge however, is in attracting enough visitors to keep the tourism industry active so that it contributes to wider development objectives, without attracting too many people so that the destination becomes over-crowded and physically and/or culturally exploited. There has been criticism that ecological aspects have been prioritised over social and cultural needs primarily because environmental issues have been on the public agenda for longer and thus, are more marketable ${ }^{9}$. However, this is not the case everywhere. Indeed, tourism is ultimately a context specific industry. Each destination has its own unique environmental, cultural and social characteristics with complex economic, human and environmental interconnections Thus, issues that may be deemed a priority for one area may not necessarily be relevant in other areas. Sustainable tourism development therefore needs to be interpreted with a certain amount of flexibility so that the individual needs of host environments and communities are catered for. Thus there may be conflicting interests, the primary concern for tourism industry professionals such as hoteliers transport and attraction providers, may be economic objectives as essentially, this is their income and source of employment. Host communities are likely to stress the importance of socio-cultural aspects so that they may improve their quality of life, alleviate poverty and preserve local culture and traditions. Environmentalists and charities however, may consider tourism harmful to the natural and physical environment and thus accentuate the protection of these natural assets.

Tourism as a system impacts both the environment and is impacted upon by the environment. Tourism can make or break the environment and to have a complimentary win win for both the economic component of tourism and the environmental component of the 
resources available, wide ranges of approaches to environmental issues based on an understanding of the complexity of the tourism system and the interrelated nature of its components must be studied. Sustainability in tourism includes economic social cultural and environmental issues and thus it is multi dimensional. The essence of sustainability and sustainable development is that they are dynamic. Tourism development thus should be a go green progress and project so that all the developmental issues relating to Tourism should consider not just economic growth but a multi dimensional approach to planning and development of the resources to the optimum capacity with maximum benefits

Sustainability is nothing but a model made for the development of tourism industry which is aimed to satisfy the requirements of the society and business. The available natural resources have to be utilised for the growth of any organisation. Similarly in tourism industry the natural resources have to be utilised optimally for the industry to sustain for a long time. The development of tourism as an industry should not exploit or misuse the available natural resources. If it does then the industry cannot sustain for a long time. If w classify resources they can be classified into natural, cultural and social resources and the major factors that are responsible for tourism industry are economic environmental and social hence for the development of tourism, a better environment is required. Hospitality industry which is a great part of tourism also depends on environmental factors for its development and growth. . Hotels and food and beverages companies should take care of natural environment around them. This optimum and judicious use of all the resources to develop is sustainability and this can be achieved only with the development of th community in which they operate. The tourism industry, the community and the government agencies should work in unison to survive and at the same time get economic benefits without tampering and damaging the existing natural and cultural resources. Tourism development has to also look into improving the conditions for local communities and the development of infrastructure.

\section{CHALLENGES FOR SUSTAINABLE TOURISM DEVELOPMENT}

The major factors or challenges for sustainable tourism is lack of potential for the development of tourism, There may also be lack of technical knowhow and knowledge. In many organisations the major challenges that is faced by sustainable tourism development is lack of awareness. Thus the challenges can be summed up as

- Lack of awareness

- Lack of knowledge and expertise

- Lack of promotional activity

- Lack of tourism infrastructure

- Lack of investment

- Lack of policy decisions

- Safety measures and lack of precautionary methods

\section{PLANNING FOR SUSTAINABILITY}

The major stages of sustainable tourism development are

- A detailed analysis of the available resources, the strengths and weakness needs to be evaluated.

- Success factors and economic returns can be assessed.

- Factors required for development needs to be assessed and evaluated like transportation, level of hospitality, cultural diversity 
- Larger goal setting like community development, increasing economic growth and focusing more on infrastructural development

- Performance evaluation in all levels social economic cultural and environment

- Requirement to improve based on the performance criteria.

\section{ISSUES TO CONSIDER IN SUSTAINABLE TOURISM}

Sustainable tourism is constantly balancing the potential profitability as against how sustainable and responsible its business model is. When it comes to the tourism sector, this makes for a complex investment strategy.

The tourism sector has various sectors within its frame work like the hotel industry, resorts, theme parks and even all the travel and tour operating sectors, there are certain common issues that affect the whole sector. Changes in climate, depletion of resources depletion or hazard to health and wellness will have impact on tourism and its attractiveness climate. Thus there are certain key issues to consider while dealing and discussing about sustainable tourism like.

\subsection{Air Pollution and Carbon Emissions}

The development of tourism industry has indirectly contributed to the increase of greenhouse gases p\particularly carbon due it increase in transportation due to tourism. Although tourism development goes hand in hand with transport development, few restrictions and cautions can be taken to protect the air pollution.

\subsection{Resource Exhaustibility}

Hotels have very high energy consumption and the increase in star rating, the increase in the use of energy levels. Heating and cooling are the major source of energy drain in hotels, there are also other luxury services like heating the pool of the spa, laundry services indoor games and recreation all contribute greatly to the increasing energy levels. Extra amenities mean that hotels with these facilities consume almost twice as much as the other hotel without these facilities.

\subsection{Job creation and Contribution to Local Economy}

Many emerging communities are regions are dependent on tourism and leisure as there major economic activity a source of income. Thus any organisation starting a tourism industry in a region has to take into consideration the locals players also.

\subsection{Working Conditions}

Sometimes, the tourism industry also exploits the local communities and there is low income levels and tough working conditions. There are several employers who are working for longer duration and there employment rues and labour laws are unorganised. s. As a result, companies often suffer from a shortage of skilled workers and face difficulties in retaining qualified staff.

\subsection{Responsible Sourcing}

Most hotels depending on outsourcing and suppliers for the needs and services and sustainability needs to consider these outsources units and suppliers as well. Sustainable development should definitively consider companies' purchasing criteria, with a particular focus on the restaurant and catering segment. Looking at food servicing, a major part of the environmental footprint is at the upstream level. 


\subsection{Franchising and Hotel Network Values}

Many hotels have come up in the franchise model and these changes in ownership models also effect the management and functioning especially in higher needs of maintaining sustainability

\subsection{Health and Wellness}

New interest in organic foods and health has created new strategies for food production and many hotels are now concentrating on these healthy new trends to make their hotel more unique. Some big fast food restaurants chain have even spent millions to offer alternative cooking methods delivering same taste with less salt, or guaranteeing non-use of hydrogenated oils. Many restaurants are now popularising their product on the basis on using healthy ingredients and in India especially many old food products are attaining new cooking styles in the name of preventing obesity and maintain health.

\subsection{Food Safety}

There is more transparency in the products used by the restaurants and contamination in any form is highly looked into and most hotels want to maintain their standard and reputations by using only branded and approved ingredients and products. Compliance to regulations, crisis management plans and proactive measures should all be examined.

\subsection{E-Security}

New digital technology has also resulted in new forms of breaches and there should be utmost protection of physical security to the client Sustainability in tourism should look at how prepared companies are to prevent attacks on clients' confidential data. The smallest of breach could result in negative reputation to the tourism industry itself.

\section{CASE STUDY REGIONS: SINGAPORE AND INDIA IN SUSTAINABLE TOURISM}

India is a developing country and there is very high yield and potential in the tourism industry. India has also emerged as the fastest growing economy of the world and there are many places that are favourable like Delhi, Agra, Jaipur, Jodhpur, Udaipur, Jaisalmer, Bikaner, Pushkar, Khajuraho, Varanasi, Kashmir, Leh and Ladakh and in the south Kerala, Mysore, Chennai etc

The islands are being seen as drivers of tourism and sustainable economic development on the lines of countries like Singapore that use water parks and natural resources to promote tourism, overcoming limited land areas while being mindful of conservation.

Given ecological sensitivity of the islands, capacities will be limited, though current options for tourists will be improved Lakshadweep, which is seen as a high end tourism destination, are limited compared to Andaman \& Nicobar. Among the islands identified are Smith Island, Ross Island, Avis Island and Long Island in Andaman \& Nicobar.

In the Lakshadweep, Bangaram, Thinnakara, Suheli, Cheriyam and Minicoy are among those slotted for development. Tourist facilities in Lakshadweep are currently limited to Bangaram and a few other islands.

The research Area selected as Chennai Being popular enclave tourism destination in India. Chennai is also a hospital city which has promoted medical tourism and health care. Political issues have greatly impacted tourism development in many parts of the world and Chennai is no exception. There are many issues related to the social, cultural and economic issues in tourists places. The wealth generated through tourism should be used for the development of the place and the tourists also should follow some ethical and moral rules and responsibility to make sure not to tamper with the environment of the tourist place. 
Singapore is the most popular tourist's destinations of the world. The tourism Industry of Singapore is a major contributor of the country's economy. The total number of tourists to Singapore is actually more than the population of Singapore. There are many reasons for the growing trend in tourism in Singapore like

- Increasing population and increasing disposable income for leisure especially in the Asian countries

- More demand for luxury goods and services which are all available in Singapore

- Cultural diversity of Singapore which attracts most people of the world.

- The nature of Singapore being clean and environmentally friendly

- English which is the language predominantly spoken in Singapore which makes it easier for the western world to communicate

- Good transportation network and good link with all parts of the world

\section{LIMITATIONS}

This research has some limitations. The first limitation is that the data used in this study are from journals, which include conference proceeding papers, master's dissertations, doctoral theses, textbooks, and unpublished working papers in the Sustainable Tourism literature. In this context any error in this data or information is also likely to affect the research. The second limitation is the comparison of case study regions between Singapore which is already at the peak of sustainability with Indian, Tamilnadu and Chennai which is a region that is just doing the baby steps in sustainable development.

\section{Tourism and Sustainability}

Over the last 60 years, tourism has evolved into the one of the worlds most powerful and remarkable socio-economic phenomena, ${ }^{18}$ An increasing number of people now have the ability, means and freedom to travel. Too many people, tourism is no longer considered a privilege but a part of an everyday life and thus, the industry has matured from being an elite activity enjoyed primarily by the upper classes to an activity enjoyed by masses every year. Sustainable tourism development is a concept heavily rooted in development theory and specifically, its parental paradigm, sustainable development "in the space of some thirty years the concept of development has evolved from a process or condition defined according to strict economic criteria to a continual, global process of human development guided by the principles of self-reliance; whilst economic growth remains a cornerstone, it also embraces social, political and cultural components." 18 This is not surprising given that a vast amount of research in this area has already been undertaken and, to date, there is little movement towards a single overriding definition.

Sustainable tourism development therefore remains a concept that is criticised for being too vague, ambiguous and open to interpretation. However, perhaps this is not necessarily a weakness. If a set definition were imposed, there is a possibility that some stakeholders may feel marginalised if their views did not align with that definition.${ }^{19}$ Just like sustainable development, sustainable tourism development is ultimately a contextual issue and therefore arriving at a definition that suits everyone everywhere is practically impossible. ${ }^{20}$. Given that it is a destination-specific concept, it is perhaps more appropriate to define it on a case by case basis ${ }^{21}$ so that the concept can be used to address widely different situations and articulate appropriate development objectives ${ }^{22}$ 


\section{CONCLUSIONS}

This Paper clearly deprives the Sustainable Tourism and its need for Chennai from the case study from comparing Singapore and its understandings by its principles and Procedures followed in Singapore and the importance need to be focused for key parameters in Improving tourism in Chennai.

\section{REFERENCES}

[1] Sharpley, R. (2000). Tourism and sustainable development: Exploring the theoretical divide.Journal of Sustainable Tourism, 8(1).

[2] Farrell, B. (1992) Tourism as an Element in Sustainable Development: Hana, Maui. In: Smith, V. \& Eadington, W. (eds) Tourism Alternatives: Potentials and Problems in the development of tourism. Philadelphia, University of Pennsylvania Press, pp. 115-134.

[3] Welford, R., Ytterhus, B. \& Eligh, J. (1999) Tourism and sustainable development: an analysis of policy and guidelines for management provision and consumption. Sustainable Development, 7, pp. 165-177.

[4] Wight, P. (2002) Supporting the Principles of Sustainable Development in Tourism and Ecotourism: Government's Potential Role. Current Issues in Tourism, 5 (3\&4), pp. 222-244.

[5] Tosun, C. (2001). Challenges of sustainable tourism development in the developing world: The case of Turkey. Tourism Management, 22, 289-303

[6] United Nations World Tourism Organization [UNWTO]. (2004). Sustainable development of tourism conceptual definition. Madrid: United Nations World Tourism Organization.

[7] Liu, C. H., Tzeng, G. H., Lee, M. H., \& Lee, P. Y. (2013). Improving metro-airport connection service for tourism development: Using hybrid MCDM models. Tourism Management Perspectives, 6, 95-107.10.1016/j.tmp.2012.09.004

[8] Cronin, L. (1990) A strategy for tourism and sustainable developments. World Leisure \& Recreation, 32 (3), pp. 12-18.

[9] Butler, R. W. (2000). Tourism and the environment: A geographical perspective. Tourism Geographies: An International Journal of Tourism Space, Place and Environment, 2, 337$358.10 .1080 / 14616680050082553$

[10] Rostow, W. (1960) The Process of Economic Growth. Oxford, Clarendon Press. Quoted in: Thirlwall, A. (2006) Growth \& development with special reference to development economies. 8th ed. Basingstoke, Palgrave Macmillan, pp. 107-114.

[11] Cohen, E. (1988) Authenticity and Commoditization in Tourism. Annals of Tourism Research, 15, pp. 371-386.

[12] Reid, D. (2003) Tourism, Globalisation and development: Responsible Tourism Planning. Pluto Press, London.

[13] Hannigan, K. (1994) A regional analysis of tourism growth in Ireland. Regional Studies, 28 (2), pp. 208-214.

[14] Briedenhann, J. \& Wickens, E. (2004) Tourism routes as a tool for the economic development of rural areas - vibrant hope or impossible dream? Tourism Management, 25, pp. 71-79. 
[15] McKercher, B. (1993) Some fundamental truths about tourism: Understanding tourism's social and environmental impacts. Journal of Sustainable Tourism, 1 (1), pp. 6-16.

[16] Cronin, L. (1990) A strategy for tourism and sustainable developments. World Leisure \& Recreation, 32 (3), pp. 12-18.

[17] Telfer, D., \& Sharpley, R. (2008) Tourism and development in the developing world. Abingdon, Routledge.

[18] Ibid P.222

[19] Sharpley, R. (2009b) The English Lake District - national park or playground? In: Frost, W. \& Hall, C.M. (eds) Tourism and National Parks: Perspectives on development, histories and change. New York, Routledge, pp. 157-183.

[20] Wall, G. (1997a) Sustainable Tourism - Unsustainable Development. In: Wahab, S. \& Pigram, J. (eds) Tourism development and growth: the challenge of Sustainability. London, Routledge, pp. 33-49.

[21] Manning, T. (1999) Indicators of tourism sustainability. Tourism Management, 20, pp. 179-181.

[22] Tosun, C. (2001). Challenges of sustainable tourism development in the developing world: The case of Turkey. Tourism Management, 22, 289-303 